was $6 \cdot 3 \%$. Repeated doses of nebulised salbutamol over the next two hours produced further bronchodilatation, the peak flow rate response rising by $14 \cdot 3 \%$ after four hours. It is therefore important to notice that large doses of nebulised $\beta$ agonist may be repeated and can produce useful bronchodilatation.

The patient who has acute severe asthma is, however, a medical emergency requiring immediate effective bronchodilator treatment. The intravenous route has perhaps been neglected in this country. This has been shown by a recently published survey of the treatment of severe asthma in the United Kingdom, in which only five of 67 hospital doctors regularly used intravenous $\beta$ agonist. ${ }^{19}$ We believe that intravenous $\beta$ agonists have a place in treating some severely asthmatic patients. It must be remembered, however, that large doses may have adverse cardiac and metabolic effects, and because of this serum potassium concentrations must be monitored and the treatment probably not used for those who have a history of myocardial disease.

We thank the nursing staff, Professor G S Kilpatrick, Dr I A Campbell, Dr B H Davies, and Dr A P Smith at Llandough Hospital for their support with this study.

1 Anonymous. Management of severe acute asthma [Editorial]. Br Med $\mathcal{J}$ $1978 ; \mathrm{i}: 873-4$.

2 Spiro SG, Johnson AJ, May CS, Paterson JW. Effect of intravenous injection of salbutamol in asthma. Br f Clin Pharmacol 1975;2:495-501.
3 Hetzel MR, Clark TJH. Comparison of intravenous and aerosol salbutamol. BrMed J 1976;ii:919.

4 Lawford P, Jones BJM, Milledge JS. Comparison of intravenous and nebulised salbutainol in initial treatment of severe asthma. $\mathrm{Br} \mathrm{Med} \mathrm{f}$ $1978 ; \mathrm{i}: 84$.

5 Bloomfield P, Carmichael J, Petrie GR, Jewell NP, Crompton GK. Comparison of salbutamol given intravenously and by intermittent positive pressure breathing in life threatening asthma. BrMed 7 1979; i 848-50.

6 Altman D. Statistics and ethics in medical research. III. How large a sample? BrMed F 1980:281:1336-8.

7 Collins JV, Clark TJH, Brown D, Townsend J. The use of corticosteroids in the treatment of acute severe asthma. Qf Med 1975;44:259-73.

8 Ward MJ. Clinical trials in acute severe asthma: are type two errors important? Thorax 1986;41:824-9.

9 Williams S, Seaton A. Intravenous or inhaled salbutamol in severe acute asthma? Thorax 1977;32:555-8

10 Tinkelman DG, Avner SE, Cooper DM. Assessing bronchodilator responsiveness. F Allergy Clin Immunol 1977;59:109-14.

11 May CS, Paterson JW, Spiro SG, Johnson AJ. Intravenous infusion of salbutamol in the treatment of asthma. Br $\mathcal{F}$ Clin Pharmacol 1975;2:503-8.

12 Williams DA, Leopold JG. Death from bronchial asthma. Acta Allergice [Copenhagen] 1959;14:83-6.

13 Fitchett $\mathrm{DH}, \mathrm{McNicol} \mathrm{MW}$, Riordan JF. Intravenous salbutamol in management of status asthmaticus. Br Med f 1975; ; :53-5.

14 Tribe AE, Wong RM, Robinson JS. A controlled trial of intravenous salbutamol and aminophylline in acute asthma. Med f Aust 1976;2:749-52.

15 Joe J, Carlsson L-G, Hetta L, Karlson B, Liungholm K. Acute asthmaplasma levels and effects of terbutaline i.v. injection. Eur $\mathcal{F}$ Respir Dis plasma levels and

16 Iodice F, Rufolo L, Piscione F, Michele G De. Hemodynamic and ventilatory effects of intravenous salbutamol in patients affected by cold. Respiration 1980;40:272-7

17 Schemin M, Koulu M, Laurikainen E, Allonen H. Hypokalaemia and other non-bronchial effects of inhaled fenoterol and salbutamol: a placebocontrolled dose-response study in healthy volunteers. $\mathrm{Br} \mathcal{f}$ Clin Pharmacol 1987;24:645-53.

8 Nogrady SG, Hartley JPR, Seaton A. Metabolic effects of intravenous salbutamol in the course of acute severe asthma. Thorax 1977;32-559-62.

19 O'Driscoll BR, Cochrane GM. Emergency use of nebulised bronchodilator drugs in British hospitals. Thorax 1987;42:491-3.

(Accepted 20 May 1988)

\title{
Epidemiology of symptomatic infections of the urinary tract in children
}

\author{
M Uhari, M Nuutinen
}

\begin{abstract}
The epidemiology of symptomatic infections of the urinary tract in children and the factors that may alter the risk of infection are not well known. Numbers of children aged under 15 discharged from hospitals because of symptomatic infections of the urinary tract during 1978-84 were obtained from the database kept by the Finnish National Board of Health. Information on continuous treatment for recurrent urinary tract infections was obtained from records kept by the Social Insurance Institution on patients receiving free medicines. The yearly rate of attacks of symptomatic infections $/ 1000$ girls decreased significantly from 2.67 (95\% confidence interval 2.52 to 2.82$)$ in 1978 to $1.88(1.76$ to 2.01$)$ in 1984. In boys the rate also decreased significantly, from $0.85(0.77$ to 0.93$)$ in 1978 to $0.59(0.52$ to 0.66$)$ in 1984. The period prevalence of free treatment/ 1000 girls decreased significantly from $7.80(7.55$ to $8.05)$ in 1978 to $5.30(5.10$ to 5.51$)$ in 1984 but did not change significantly in boys.
\end{abstract}

Although the findings may partly have been caused by changes in policies of admission to hospital, they suggest a decreasing trend in symptomatic urinary tract infections in childhood, which may be associated with changes in the care of infants.

Department of Paediatrics, University of Oulu, SF-90220 Oulu, Finland Matti Uhari, MD, associate professor

Matti Nuutinen, MD, training fellow

Correspondence to: Dr Uhari. treatment in hospital for urinary tract infections, though Winberg et al found a significant but unexplained increase in the total number of children admitted to hospital because of symptomatic urinary tract infections during 1952-66. Susceptibility to infection is poorly understood, and changes in susceptibility with time may point to important environmental or behavioural factors that can alter the risk of infection.

To monitor epidemiological trends we analysed information available nationally on children admitted to hospital with urinary tract infections and on the use of preventive treatment for such infections.

\section{Patients and methods}

The Finnish National Board of Health keeps a central database recording the age, sex, and main diagnosis of patients discharged from all hospitals in Finland. From this we compiled figures for children aged under 15 who had been treated for symptomatic urinary tract infections during 1978-84. The data were readily available in the three age groups $0-4,5-9$, and 10-14 for boys and girls separately. Almost all children under the age of 1 are admitted to hospital when they have a symptomatic urinary tract infection and figures for these children were therefore collected separately from the same database. In Finland children receiving prophylactic treatment because of recurrent urinary tract infections are permitted free medicines, and the Social Insurance Institution keeps records of all patients receiving free treatment. From this source we collected information yearly on children receiving continuous treatment for recurrent urinary tract infections. 
Numbers of bacterial cultures obtained from samples of urine taken in this department from children admitted to hospital and the types of bacteria isolated were determined from the records of the bacteriology laboratory for each year.

Statistical methods-The discharge figures we obtained represent the yearly rate of attack (first and recurrent infections combined). The number of children at risk was determined from the yearly census; about 60000 children are born each year in Finland. As children accounted for all patients receiving preventive treatment for urinary infections at any time during the year the numbers in this category represent the period prevalance. ${ }^{6}$ All figures were assumed to follow a Poisson distribution, and the $95 \%$ confidence intervals were calculated on this assumption. ${ }^{7}$ Trend was assessed by $\chi^{2}$ analysis.

\section{Results}

The rate of attacks of symptomatic urinary tract infections/1000 girls of all ages decreased steadily and significantly by about a third from 1978 to 1984 (from 2.67 (95\% confidence interval 2.52 to $2 \cdot 82$ ) to 1.88 $(1 \cdot 76$ to $2 \cdot 01)$; test for trend, $\mathrm{p}<0.001)$ (table I). The decrease was seen in all age groups and was most evident among the age group 0-4 (figure). In boys the attack rate also decreased significantly from 1978 to 1984 (from $0.85(0.77$ to 0.93$)$ to $0.59(0.52$ to 0.66$)$; test for trend, $\mathrm{p}<0.001$ ) (table I). The decline was significant in each age group, except that of 10-14, in which the rate remained low and constant (figure).

The rate of attack in childen aged under 1 was

TABLE I-Rate of attacks ${ }^{\star}$ ( $95 \%$ confidence intervals) of symptomatic urinary tract infections in children under 15 (age groups combined) discharged from all hospitals in Finland, 1978-84

\begin{tabular}{lccccc}
\hline & \multicolumn{3}{c}{ Girls } & & \multicolumn{2}{c}{ Boys } \\
\cline { 2 - 3 } \cline { 5 - 6 } Year & $\begin{array}{c}\text { No of } \\
\text { children }\end{array}$ & Rate of attacks & & $\begin{array}{c}\text { No of } \\
\text { children }\end{array}$ & Rate of attacks \\
\hline 1978 & 1293 & $2.67(2.52$ to 2.82$)$ & & 428 & $0.85(0.77$ to 0.93$)$ \\
1979 & 1243 & $2.60(2.46$ to $2 \cdot 75)$ & & 411 & $0.82(0.75$ to 0.91$)$ \\
1980 & 1170 & $2.48(2.34$ to 2.63$)$ & & 384 & $0.78(0.70$ to 0.86$)$ \\
1981 & 1062 & $2.27(2.14$ to 2.41$)$ & & 388 & $0.79(0.72$ to 0.88$)$ \\
1982 & 1049 & $2.26(2.12$ to 2.40$)$ & & 330 & $0.68(0.61$ to 0.76$)$ \\
1983 & 868 & $1.87(1.75$ to 2.00$)$ & & 348 & $0.72(0.64$ to 0.80$)$ \\
1984 & 873 & $1.88(1.76$ to 2.01$)$ & & 285 & $0.59(0.52$ to 0.66$)$ \\
\hline
\end{tabular}

*Number having infection/1000 at risk/year. Test for trend in both groups, $\mathrm{p}<0.001$.
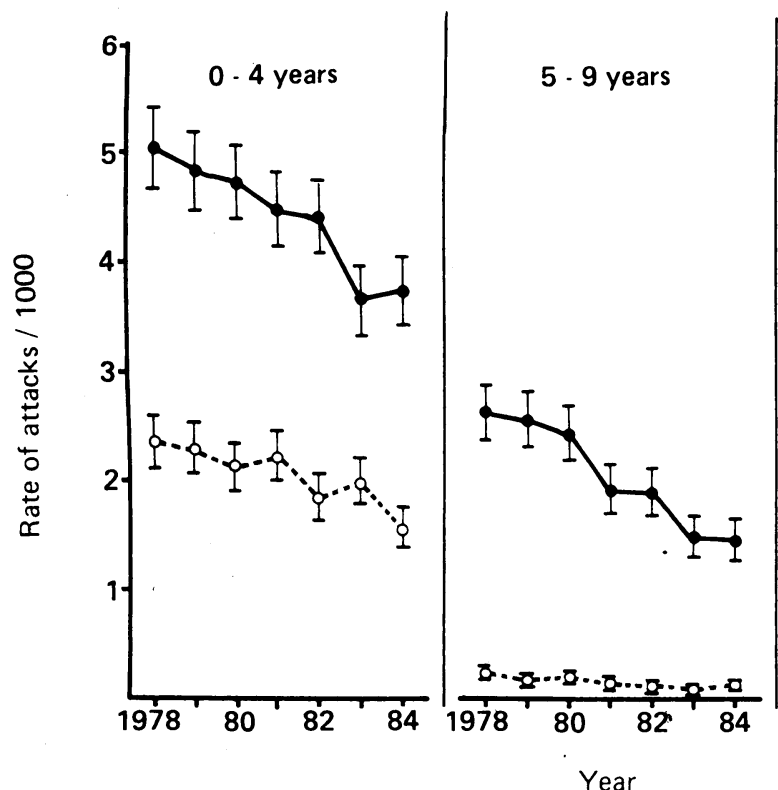

$10 \cdot 14$ years

Year

Rate of attacks of symptomatic urinary tract infection in children under 15 by age group, 1978-84. Bars are $95 \%$ confidence intervals similar in girls and boys, the combined rate decreasing significantly during the study from $8 \cdot 91(8 \cdot 21$ to $9 \cdot 67)$ to $6.72(6.11$ to $7 \cdot 38)(\mathrm{p}<0.001)$.

The period prevalence of treatment for girls- that is, the number of girls receiving free treatment at any time during the year in question $/ 1000$ at riskdecreased significantly from $7 \cdot 80(7 \cdot 55$ to 8.05$)$ to $5 \cdot 30$ $(5 \cdot 10$ to $5 \cdot 51)(\mathrm{p}<0.001)$ (table II). The decline was continuous but was steeper during the last three years of the study. Again the decrease was seen in all age groups. No significant change in the period prevalence was found in boys either overall (table II) or by age group.

The number of urine samples examined each year varied from 2624 to 2947 . The number that gave positive results on bacterial culture-that is, $>10^{5}$ colonies/ml urine-declined appreciably from 1978 to 1984 , but the proportion of bacterial types remained almost the same.

TABLE II-Period prevalence ${ }^{\star}(95 \%$ confidence intervals) of free treatment in children under 15 of recurrent urinary tract infections (age groups combined)

\begin{tabular}{lccccc}
\hline & \multicolumn{2}{c}{ Girls } & & \multicolumn{2}{c}{ Boys } \\
\cline { 2 - 3 } \cline { 5 - 6 } Year & $\begin{array}{c}\text { No of } \\
\text { children }\end{array}$ & $\begin{array}{c}\text { Period } \\
\text { prevalence }\end{array}$ & & $\begin{array}{c}\text { No of } \\
\text { children }\end{array}$ & $\begin{array}{c}\text { Period } \\
\text { prevalence }\end{array}$ \\
\hline 1978 & 3774 & $7 \cdot 80(7.55$ to 8.05$)$ & & 438 & $0.87(0.79$ to 0.95$)$ \\
1979 & 3671 & $7.69(7.45$ to 7.94$)$ & & 469 & $0.94(0.86$ to 1.03$)$ \\
1980 & 3528 & $7.48(7.23$ to $7 \cdot 73)$ & & 485 & $0.98(0.90$ to 1.07$)$ \\
1981 & 3466 & $7.41(7.17$ to 7.66$)$ & & 483 & $0.99(0.90$ to 1.08$)$ \\
1982 & 3239 & $6.96(6.73$ to 7.21$)$ & & 505 & $1.04(0.95$ to 1.13$)$ \\
1983 & 2900 & $6.25(6.02$ to 6.48$)$ & & 489 & $1.01(0.92$ to 1.10$)$ \\
1984 & 2464 & $5.30(5.10$ to 5.51$)$ & & 462 & $0.95(0.87$ to 1.04$)$ \\
\hline
\end{tabular}

${ }^{\star}$ No of children receiving continuous treatment/1000 at risk/year. Test for trend, $\mathrm{p}<0.001$ in girls.

\section{Discussion}

Both the rate of attacks of symptomatic infections of the urinary tract and the period prevalence of free treatment provided for recurrent infections declined significantly from 1978 to 1984 . Winberg et al observed a steep increase in morbidity from urinary tract infections from 1952 to 1966 and suggested that the main reason was an increased awareness of this type of infection..$^{5}$

We do not think that the criteria for diagnosing symptomatic infections and for recommending preventive treatment changed during the study. Preventive treatment was started if the child had had three or more infections during six months. The indications for continuous chemotherapy in children with malformations of the urinary tract remained the same during the study, but the treatment given was decided individually. New, more effective antibiotics against Gram negative organisms have become available, but most of them can be given only parenterally and thus are used solely in hospital. Trimethoprim and sulphamethoxazole combined was widely used by general practitioners during the study.

The rate of attacks of urinary tract infections in girls has been estimated to be 10 times that in boys, except in infancy, when the rates are about the same. ${ }^{3}$ Our estimate of the rate in the girls, calculated from the discharge figures, was about three times that in the boys.

Wiswell and Roscelli gave the incidence of acute urinary tract infections during the first year of life as $0.57 \%$ in girls and $1.12 \%$ and $0.11 \%$ in uncircumcised and circumcised boys respectively. ${ }^{8}$ The incidence in uncircumcised boys is similar to our result for 1978, when it was $9 \cdot 29 / 1000$, though the value in our study had declined to $5 \cdot 99 / 1000$ by 1984 . Among girls our results varied from $9 \cdot 46 / 1000$ to $6 \cdot 72 / 1000$, which was close to the figure reported by Wiswell and Roscelli. ${ }^{8}$ 
Epidemiological data such as ours are vulnerable to many sources of bias. Outpatient facilities at health centres improved during the study, but this should have had only a minor effect on the rate of attack in children under 1 and no effect on the prevalence of free treatment. The ratio of prevalence of free treatment to rate of attack remained constant at 2.9 in 1978 and 2.8 in 1984, suggesting that the criteria for admission to hospital did not change during the study. The data from all three of our sources consistently showed an appreciable decrease in the rates of infection.

We could not collect any data on possible factors leading to the decline in urinary tract infection. One important possible factor is the simultaneous improvement in the diagnosis of such infections: their diagnosis, treatment, and consequences have been subjects of postgraduate courses for both general practitioners and paediatricians. In the light of our results showing a continuous decline in the treatment of urinary tract infections, both in hospitals and by continuous treatment, a hypothesis of an improvement in diagnosis suggests that medical practice has been unsatisfactory. The decrease we observed in the number of urine samples giving positive results on bacterial culture is, however, difficult to explain in terms of improvements in diagnosis.

It is tempting to connect our findings with the simultaneous changes in the care of infants. In particular, the use of napkins changed appreciably during the study, disposable napkins of better quality being used increasingly. The impression of paediatricians working in developing countries where napkins are not used is that the rate of urinary tract infections is low. ${ }^{2}$ A child who has had one symptomatic infection runs an increased risk of having another for a long time afterwards." Thus factors affecting the disease in early infancy could be reflected in its occurrence even in later childhood. We suggest that the decrease in symptomatic urinary tract infections shown by our results may be associated with changes in caring for infants.

This survey was supported by grants from the Alma och K A Snellman Foundation and the Finnish Kidney Association.

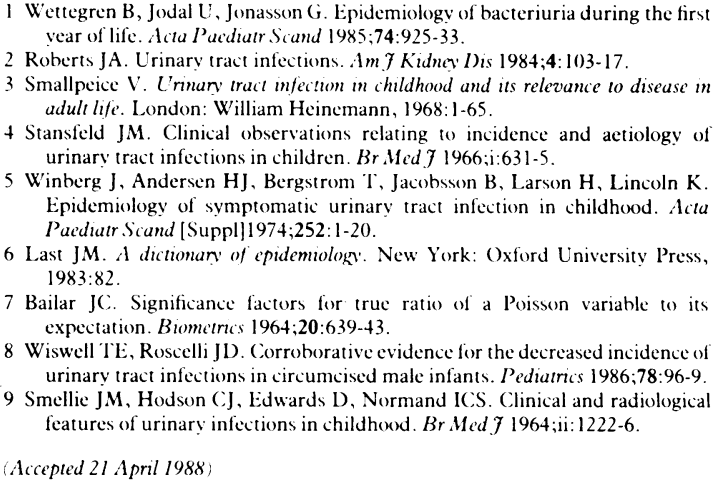

\section{Painful crises in sickle cell disease_patients' perspectives}

\author{
Nigel Murray, Alison May
}

\begin{abstract}
One hundred and two patients returned structured questionnaires sent to clinics for sickle cell disease in the United Kingdom in order to gain greater insight into the patients' perception of painful crises. Most patients who suffer pain crises experience a prodromal stage that should be investigated further to find out if prophylaxis is possible. Cold, exertion, and tiredness were the most important precipitating factors. Despite the increase in the amount of knowledge about sickle cell disease in recent years, and though 29 out of 88 patients $(30-40 \%)$ believed that medical services were improving, 33 out of 88 $(30-40 \%)$ were still experiencing long delays in being treated in hospital. A third of patients do not seem to receive adequate pain relief.
\end{abstract}

\section{Introduction}

Sickle cell disease is common in urban areas; in London alone there are nearly 2000 patients.' Painful vaso-occlusive crises account for nearly all the acute hospital admissions of patients with sickle cell disease in the London area. ${ }^{2}$ These episodes vary in severity and duration within the same patient as well as between individual patients. ${ }^{3}$ The physical signs and symptoms have been extensively reviewed but much remains to be learned about the patients' own perceptions of their illnesses. This paper describes an attempt to collect information from patients on various aspects of management of pain crises both at home and in hospital.

\section{Patients and methods}

A structured questionnaire was used to obtain information about age, sex, the patients' awareness of incipient sickling crises and measures taken to avert or control them, previous sources of health education, the accessibility and adequacy of medical care, and perception of factors causing crises and measures taken to reduce the pain.

Information about the intensity of pain during the patient's last crisis, about the problems of the doctors' and nurses' understanding of the amount of pain, and about the problems of sickle cell disease, were obtained with a 0-5 linear analogue scale. A 0-3 linear analogue scale was used to measure patients' perception of pain relief. Other questions were answered by ticking the appropriate box, and space was left for additional comments. More than one answer to particular questions could be given.

The data were collected over the three months June to September 1986 from patients attending sickle cell and haematology clinics in London, Birmingham, and Manchester. The diagnostic criteria have been summarised by Serjeant. ${ }^{+}$Four hundred questionnaires were sent to the clinics for distribution, and 102 patients ( 61 women and 41 men) aged between 11 and 49 years returned the questionnaire. The response rate is unknown because the number of questionnaires given to patients is unknown. Of the responders, 77 were homozygous for haemoglobin $S, 21$ were doubly heterozygous for haemoglobin $S$ and haemoglobin $C$, one had haemoglobin $S-\beta$ thalassaemia, one was doubly heterozygous for haemoglobin $S$ and haemoglobin J, and two had sickle cell disease but were uncertain of their genotypes. Three of those homozygous for haemoglobin $S$, five who were homozygous for haemoglobin $S$ and haemoglobin $\mathrm{C}$, and both those of unknown genotype, had never had a painful crisis. A further four patients who were homozygous for haemoglobin $S$ had not been admitted to hospital because of a painful crisis. 